\title{
Pattern of breast feeding practices in a selected rural area of Bangladesh
}

\begin{abstract}
Background: Breastfeeding is the normal way of providing infants with nutrients for healthy growth and development. Exclusive breastfeeding means the infant receives no solids or liquids apart from breast milk with the exception of vitamins, minerals, or medicines. But improper and lack of practices of breastfeeding give lifetime punishment to the child and also to mother.
\end{abstract}

Objective: The aim of this study was to assess pattern of breast feeding practices in a selected rural area.

Methods: It was a cross sectional observational study. A total of 400 subjects were estimated purposively and mothers having children aged between $0-6$ months of age was included. A pretested questionnaire was used to collect data.

Results: The mean $( \pm \mathrm{SD})$ age of the respondents was 24 .4years. Among mothers more than half $(58.5 \%)$ of the respondents practiced only breast milk. Combination of breast milk and artificial milk was also practiced by $22.8 \%$ respondents. Most of the mother $(34.8 \%)$ fed breast milk $12-15$ times in a day whereas $29.5 \%$ mothers fed breast milk to their child according to demand. Practices of other foods besides breast milk were common among $39.3 \%$ mothers. Complimentary food with cow's milk and Suji were practiced by $28.3 \%$ mothers. Sex, family member, family type, birth order, mode of delivery, birth attendants were significantly associated with initiation of breast feeding.

Conclusion: The breast feeding practices of rural women need to be further improved. Health education and health promotion programme regarding breast feeding practices should be constituted effectively and appropriately.

Keywords: pattern, breast feeding practices, rural area
Volume 2 Issue 2 - 2015

\author{
Mohammad Shahinoor Islam \\ Department of Community Nutrition, Bangladesh University of \\ Health Sciences, Bangladesh
}

Correspondence: Mohammad Shahinoor Islam, Faculty of Public Health, Department of Community Nutrition, Bangladesh University of Health Sciences (BUHS), I25/I, Darus Salam, Mirpur, Dhaka-1216, Bangladesh, Tel +00 88 0I7I2563385, Email rshahin21@gmail.com

Received: January 12, 2014 | Published: June 03, 2015
Abbreviations: WHO, world health organization; BADAS, diabetic association of Bangladesh; BDHS, Bangladesh demographic and health survey; EBF, effective breast feeding; UNICEF, united nations children's fund

\section{Introduction}

Without perfect nutrition no one can survive perfectly even a microbe. Childhood morbidity and mortality is still global burden and a health challenging problem of Bangladesh and it starts from early infancy. When feeding is necessary after coming to the beautiful world from the mother's womb only one food that fulfill babies need without creating any hazards and that is only breast milk. But there was a great inconsistency regarding optimal breastfeeding practices worldwide till now. A recent estimate by World Health Organization (WHO) showed that worldwide only $35 \%$ of children between birth and their 5 th month are exclusively breastfed. ${ }^{1}$ Improper and lack of practices of breastfeeding give lifetime punishment to the child and also to mother.

In Bangladesh, infectious diseases, like diarrhea and acute respiratory tract infections are cause of more than two-thirds of all deaths in children aged below one year. ${ }^{2}$ According to WHO worldwide increase in breastfeeding rates by $40 \%$ would reduce respiratory deaths by $50 \%$ and diarrhea by $66 \%$ in infants aged less than 18 months. ${ }^{3}$ It has been estimated that optimal breastfeeding of children under two years of age has the potential to prevent 1.4million deaths in children under five in the developing world annually. ${ }^{4}$ Some studies termed exclusive breastfeeding as the most effective global public health intervention for child survival., ${ }^{5,6}$ According to the Bangladesh Demographic and Health Survey 2011 practices of exclusive breastfeeding was $64 \% .^{7}$ Based on the Infant Feeding Survey conducted in 2010, the estimated breastfeeding initiation rate in Scotland was $74 \%$. This was a significant increase from rates reported in $2000(55 \%)$ and compared favorably with initiation rates in England (82\%), Wales (71\%), and Northern Ireland (64\%). ${ }^{8}$ But current breastfeeding patterns are far below the recommended levels especially in Africa and Asia where rates of exclusive breastfeeding for the first six months are less than $40 \% .{ }^{9}$ The aim of this study was to assess pattern of breast feeding practices in selected rural area.

\section{Methodology}

\section{Study design}

A cross sectional study was done.

\section{Study period}

The study period was one year duration from July 2012 to June 2013.The study was started with protocol preparation and finished through final report submission. 


\section{Study population}

Mothers having children aged between 0-6months of age.

\section{Study area}

The study area was selected purposively. The study was conducted in Nawabgonj upazila located in the south-western corner of Dhaka district which was the biggest upazila located about 45kilometers away from city. Most families earned from job in abroad. There was a government primary health care centre which offers antenatal care, immunization and pediatric out-patient services. Majority of the people got health care facilities from private hospital. While most deliveries occurred in private clinic, some deliveries occurred at home attended by traditional birth attendant. EPI centers were selected for data collection. The informed consent of the subjects was obtained before data collection.

\section{Sample size}

A total of 400 subjects were estimated.

\section{Sampling technique}

Total 400 mothers were selected purposively from the three union of Nawabgonj Upazilla in Dhaka district.

\section{Data collection techniques}

Face to face interview was used for data collection.

\section{Data processing \& analysis}

All interview forms were reviewed and individual questionnaire was checked and cleaned to avoid any possible mistakes. After checking the completeness, coding was done. Data entry, cleaning, editing and final analysis was done in SPSS version 15.0. Descriptive as well as inferential statistics were used to present data.

\section{Ethical considerations}

i. Ethical guideline of Diabetic Association of Bangladesh (BADAS) was followed throughout the study.

ii. Informed written consent was taken from every respondent after full explanation of the nature and purpose of the study.

iii. Subjects were free to withdraw from the study at time they liked to do.

iv. The questionnaire was designed considering the privacy of the subjects.

v. Personal information kept confidential.

\section{Result}

Socio demographic characteristics of mothers were summarized in Table 1 . The mean $( \pm \mathrm{SD})$ age of the mothers was 24.4 years. Majority of the respondents $(75.3 \%)$ were Muslims. About half of the participants $(54.5 \%)$ lived with nuclear family whereas $42.3 \%$ belonged to joint family. About $22 \%$ mother had 4 family members and 59\% had 3-6 family members. Majority of the respondents (35\%) had good income 15000-25000 BDT per month. About 23.5\% mother completed higher secondary level of education but majority of the mother (39.5\%) had secondary level. Most of the respondents (83.8\%) were housewife and a small portion $(11.0 \%)$ was service holder. Table 2 showed pattern of breast feeding practices. More than half of the respondents $(58.5 \%)$ practiced only breast milk but combination of breast milk and artificial milk was practiced by $22.8 \%$ respondents. Most of the mothers (34.8\%) fed breast milk 12-15times in a day whereas $29.5 \%$ mothers fed breast milk to their child according to demand. Practices of other foods beside breast milk were common among $39.3 \%$ mothers.

Table I Socio-demographic characteristics of respondents $(n=400)$

\begin{tabular}{ll}
\hline Variables & Percentage (\%) \\
\hline Age( year ) & \\
Mean \pm SD 24.44 \pm 4.93 & \\
Family member & \\
6-Mar & 59.8 \\
I0-Jul & 39.8 \\
Family type & \\
Nuclear & 54.5 \\
Joint & 45.6 \\
Religion & \\
Muslim & 75.3 \\
Hindu & 23.8
\end{tabular}

Monthly family income in BDT

15,000

$15,000-25,000$

35

More than 25,000

Birth Order of Child

I

3

7

4

Preceding Birth Interval

No Previous Birth $\quad 63.5$

15 month

16-24month

$>25$ month

II

Education

No Formal Education ।

Primary 20

SSC $\quad 46.5$

HSC $\quad 23.8$

Graduate and Above $\quad 8.8$

Occupation

Housewife $\quad 84$

Service $\quad$ II

Others 5 
Table 2 Pattern of breastfeeding practices $(n=400)$

\begin{tabular}{|c|c|c|}
\hline Characteristics & Frequency & $\%$ \\
\hline \multicolumn{3}{|l|}{ Types of feeding } \\
\hline Only Breast Milk & 234 & 58.5 \\
\hline Breast Milk and Artificial Milk & 91 & 22.8 \\
\hline Only Artificial Milk & 40 & 10 \\
\hline Cows and Goat Milk & 29 & 7.3 \\
\hline Breast Milk and Water & 3 & 0.8 \\
\hline Others & 3 & 0.8 \\
\hline \multicolumn{3}{|l|}{ Frequency of breast feeding } \\
\hline 6-8times & 57 & 14.3 \\
\hline 9-I I times & 28 & 7 \\
\hline $12-15$ times & 139 & 34.8 \\
\hline Breast Feeding on Demand & 118 & 29.5 \\
\hline \multicolumn{3}{|l|}{ Types of other feed } \\
\hline Cow's Milk and Suji & 113 & 28.3 \\
\hline Artificial Milk \& Others & 39 & 9.8 \\
\hline Cow's Milk and Rice Bran & 16 & 4 \\
\hline
\end{tabular}

Table 3 showed initiation of breast feeding. Majority of the respondents $(36.8 \%)$ did not remember the time of breastfeeding initiation and $31.8 \%$ practiced timely initiation within one hour after birth and on the other hand $31.5 \%$ of the respondent initiated breastfeeding more than 1 hour after birth. Different socioeconomic variables showed significant association $(\mathrm{p}<0.05)$ with initiation of breastfeeding (Table 4 ). It was observed that $47.7 \%$ and $54.9 \%$ mother initiated breastfeed within one hour after birth and more than one hour respectively. Both of those were statistically significant $(p<0.05)$. About $57.3 \%$ mother lived in nuclear family. More than two third of the mothers $(75.6 \%)$ were influenced by the non health professionals to initiate breastfeeding after one hour after birth.

Table 3 Distribution of the time of breastfeeding initiation

\begin{tabular}{lll}
\hline Characteristics & Frequency & $\%$ \\
\hline Within One Hour After Birth & 127 & 31.8 \\
More Than Ihour & 126 & 31.5 \\
Don't Remember & 147 & 36.8 \\
\hline
\end{tabular}

Table 4 Association of initiation of breast feeding practices with different variables

\begin{tabular}{|c|c|c|c|c|}
\hline \multirow[t]{2}{*}{ Variables } & \multicolumn{2}{|c|}{ Initiation of breast feeding } & \multirow[t]{2}{*}{$\chi^{2}$ Value } & \multirow[t]{2}{*}{ PValue } \\
\hline & $\begin{array}{l}\text { Within } \\
\text { I hour }\end{array}$ & $\begin{array}{l}\text { More than } \\
\text { Ihour }\end{array}$ & & \\
\hline Children's Sex & $N(\%)$ & $N(\%)$ & 10.92 & 0.001 \\
\hline Male & $91(37.6)$ & $|5|(62.4)$ & & \\
\hline Female & $86(54.4)$ & $72(45.6)$ & & \\
\hline \multicolumn{5}{|c|}{ Age of the Respondent } \\
\hline $17-25$ & $12 \mid(45.1)$ & $147(54.9)$ & & \\
\hline $26-34$ & $52(47.7)$ & $57(52.3)$ & 1.61 & 0.035 \\
\hline $35-43$ & $4(19.0)$ & $17(81.0)$ & & \\
\hline \multicolumn{5}{|l|}{ Family Member } \\
\hline 6-Mar & $102(42.7)$ & $137(57.3)$ & 0.605 & 0.001 \\
\hline I0-Jul & $74(46.5)$ & $85(53.5)$ & & \\
\hline \multicolumn{5}{|l|}{ Family Type } \\
\hline Nuclear & $93(42.7)$ & $125(57.3)$ & 0.491 & 0.001 \\
\hline Joined & $84(46.2)$ & $98(53.8)$ & & \\
\hline \multicolumn{5}{|l|}{ Birth Order } \\
\hline First Mother & $130(50.6)$ & $127(49.4)$ & 11.69 & 0.001 \\
\hline Second Time & $47(32.9)$ & $96(67.1)$ & & \\
\hline \multicolumn{5}{|c|}{ Influencer to Take Artificial Milk } \\
\hline $\begin{array}{l}\text { Non- health } \\
\text { Professionals }\end{array}$ & $32(24.4)$ & $99(75.6)$ & 9.89 & 0.002 \\
\hline Health Professionals & $19(51.4)$ & $18(48.6)$ & & \\
\hline \multicolumn{5}{|l|}{ Religion } \\
\hline Muslim & $\mid 25(4 \mid .5)$ & $176(58.5)$ & 3.65 & 0.05 \\
\hline Non Muslim & $52(52.5)$ & $47(47.5)$ & & \\
\hline \multicolumn{5}{|c|}{ Delivery Attendants } \\
\hline Doctors/Nurse & $\mid 48(4 \mid .5)$ & $209(58.5)$ & 10.5 & 0.001 \\
\hline TBA and others & $29(67.4)$ & $14(32.6)$ & & \\
\hline \multicolumn{5}{|l|}{ Mode of Delivery } \\
\hline Normal & $64(57.1)$ & $48(42.9)$ & 13.17 & 0.001 \\
\hline Caesarean & $113(39.2)$ & $175(60.8)$ & & \\
\hline
\end{tabular}

\section{Discussion}

Lack of optimal breastfeeding practices is a serious public health concern all over the world. The prevalence of exclusive breastfeeding practices is increasing day by day worldwide but not fulfills the target criteria. According to BDHS 2011 in Bangladesh it was estimated that the prevalence of EBF was $64 \%$. Optimal infant and young child feeding especially exclusive breastfeeding has a highly protective effect against both illnesses of ARI and diarrhea ${ }^{10}$ and decreased childhood morbidity and mortality. ${ }^{11}$ According to UNICEF 39\% of newborns were put into the breast within lhour after birth, the 
rate was low in Asia (31\%). ${ }^{12}$ In this study $31.8 \%$ mothers initiated breastfeeding within one hour after birth and $31.5 \%$ fed breast milk more than one hour after birth which was almost same as observed in Nepal (35.4\%) and higher than a study showed in Bangladesh (27.5\%) but lower than Sri Lanka (56\%). ${ }^{13}$ But tremendous result was seen in a study that $80.4 \%$ mothers initiated breast feeding within one hour as recommended..$^{14}$ Delayed initiation of breastfeeding was common in Bangladesh but rates of initiation had improved in recent years. Another study conducted in Bangladesh reported similar finding. ${ }^{15}$ Initiation of breastfeeding on the third day or later was also practiced. In 1996 a study conducted at rural women and showed 27\% women initiated breastfeeding on the third day or later. ${ }^{16}$ A study from Ghana revealed $22 \%$ of all neonatal deaths could be prevented if all women could initiate breastfeeding within one hour after birth. ${ }^{17}$ There was significant association with child sex and early initiation of breastfeeding $(p<0.05)$. In this study female children were 1.8 imes more strongly associated than male in initiation of breastfeeding within one hour after birth. Delivery assistance and mode of delivery also had significant association $(\mathrm{p}<0.05)$. A study in Benin showed early initiation of breastfeeding was $50 \%$. About $58 \%$ delivery was done by TBAs and health professionals. ${ }^{18}$ Influence to take artificial feeding by the non medical person like grandmother, mother in laws was associated with early initiation of breastfeeding $(p<0.05)$. Kessler et al., ${ }^{19}$ reported that $71 \%$ mothers were influenced by the infant's father and $29 \%$ by the maternal grandmother. Heather ${ }^{20}$ found that children born at home were significantly more likely than children born at private hospitals to initiate breast-feeding early.

\section{Conclusion}

The study attempted to determine pattern of breastfeeding practices in a rural area like Nawabgonj thana in Bangladesh. Among mothers more than half of the respondents $(58.5 \%)$ practiced only breast milk but combination of breast milk and artificial milk was also practiced by $22.8 \%$ respondents. Most of the mother (34.8\%) had given breast milk 12 -15times in a day whereas $29.5 \%$ mothers fed breast milk to their child according to demand. So overall scenario need to be improved.

\section{Acknowledgements}

None.

\section{Conflict of interest}

Author declares that there is no conflict of interest.

\section{References}

1. WHO. The State of Breastfeeding in 33 Countries. 2010.

2. World Health Organization. Division of Child Health and Development, Indicators for assessing breast-feeding practices: Report of informal meeting. Geneva, Switzerland; 1991:1-16.

3. Hanson LA, Korotkova M, Håversen L, et al. Breastfeeding, a complex support system for the offspring. Pediatr Int. 2002;44(4):347-354.
4. Black RE, Allen LH, Bhutta ZA, et al. Maternal and child under nutrition: global and regional exposures and health consequences. Lancet. 2008;371(9608):243-260.

5. Jones G, Steketee RW, Black RE, et al. How many child deaths can we prevent this year? Lancet. 2003;362(9377):65-71.

6. Darmstadt GL, Bhutta ZA, Cousens S, et al. Evidence-based, costeffective interventions: how many newborn babies can we save? Lancet. 2005;365(9463):977-988.

7. National Institute of Population Research and Training. Bangladesh Demographic and Health Survey 2011. Dhaka, Bangladesh; 2013. p. 165-184.

8. The National Information Centre. Infant feeding survey report 2010, Early results. IFF Research. 2011.

9. Lauer JA, Betran AP, Victora CG, et al. Breastfeeding patterns and exposure to suboptimal breastfeeding among children in developing countries: review and analysis of nationally representative surveys. BMC Med. 2004;2:26.

10. Mihrshahi S, Ichikawa N, Shuaib M, et al. Prevalence of exclusive breastfeeding in Bangladesh and its association with diarrhea and acute respiratory infection: Results of the multiple indicator cluster survey 2003. J Health Popul Nutr. 2007;25(2):195-204.

11. Morisky DE, Kar SB, Chaudary AS, et al. Breast feeding Practices in Pakistan. Pakistan Journal of Nutrition. 2002;1(3):137-142.

12. UNICEF. Tracking progress on child and maternal nutrition. A survival and development priority. New York, USA; 2009. p. 1-124.

13. Senarath U, Dibley MJ, Godakandage SSP, et al. Determinants of infant and young child feeding practices in Sri Lanka: secondary data analysis of Demographic and Health Survey 2000. Food Nutr Bull. 2000;31(2):352-365.

14. Passing Lahmo, Sherpa. Determinants of breastfeeding practices among maternal and child health clinic (MCH) in JDWNR hospital. Thimpu, Bhutan; 2007.

15. Ahmed MS. Intimate partner violence against women: Experience from a woman-focused development programme in Matlab. Bangladesh. Journal of Health, Population and Nutrition. 2003;23(1):95-101.

16. Baqui AH, Paljor N, Nahar Q, et al. Infant and child feeding practices in Dhaka urban slums. Dhaka, Bangladesh: ICDDRB; 1993:1-42.

17. Dadhich JP, Agarwal RK. Mainstreaming early and exclusive breastfeeding for improving child survival. Indian Paeditr. 2009;46(1):11-17.

18. Mangasaryan N, Martin L, Brownlee A, et al. Breastfeeding Promotion, Support and Protection: Review of Six Country Programmes. Nutrients. 2012;4(8):990-1014

19. Kessler LA, Gielen AC, Diener-West M, et al. The effect of a woman's significant other on her breastfeeding decision. J Hum Lact 1995;11(2):103-109.

20. Heather LS. Infant feeding practices and beliefs among women in Podor, West Africa. Master's Thesis Paper 3629. 2008. 